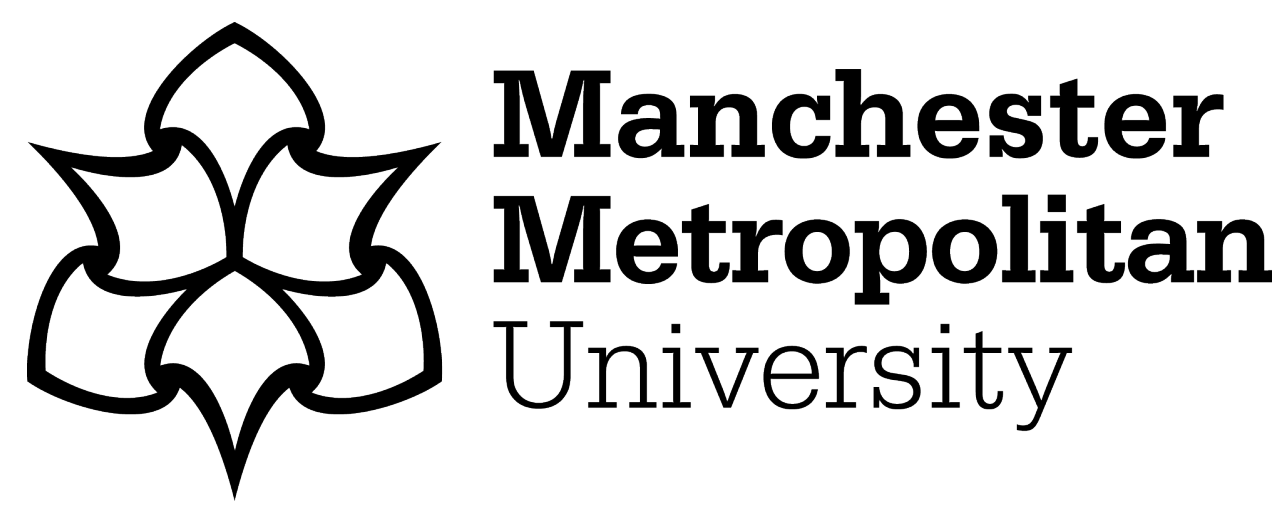

Campbell, Sarah ORCID logoORCID: https://orcid.org/0000-0002-29207318, Ponsillo, Nick, Budd, Paul and Keady, John (2017) "Music in Mind" and Manchester Camerata: an exploratory qualitative evaluation of engagement in one care home in Northwest England. Quality in Ageing and Older Adults, 18 (1). pp. 69-80. ISSN 1471-7794

Downloaded from: https://e-space.mmu.ac.uk/625029/

Version: Accepted Version

Publisher: Emerald

DOI: https://doi.org/10.1108/qaoa-01-2016-0001

Please cite the published version 


\title{
"Music in Mind" and Manchester Camerata: an exploratory qualitative evaluation of engagement in one care home in Northwest England
}

\author{
Sarah Campbell, Nick Ponsillo, Paul Budd and John Keady
}

\begin{abstract}
Purpose - The purpose of this paper is to consider the work conducted by Manchester Camerata (an internationally renowned and world-class chamber orchestra) programme for people with dementia in one care home in the north west of England. The study aim was to undertake an exploratory qualitative evaluation of experiences of those taking part in its ten week "Music in Mind" programme, namely care home staff, Manchester Camerata musicians/organisational staff, care home activity workers, the assigned music therapist and visiting family carers.

Design/methodology/approach - During July-September 2014 a sample of 11 participants was recruited and a total of 19 interviews conducted over ten weeks. All respondents were offered the opportunity to be interviewed more than once. Interview data were supplemented by information gathered at two musicians de-brief sessions and from two activity workers' diaries. All data was organised using NVivo 10 and thematic analysis applied to the whole data set. People with dementia could not be included in the sample owing to the time limitations on starting and completing the evaluation.

Findings - This analytical process generated three overarching themes: Making it Happen, which referred to the contextual, structural and organisational considerations necessary for setting up the engagement programme; Orchestrating Person-centred Care, which addressed the importance of building relationships through person to person communication; Making Musical Connections, which identified the sensory and embodied qualities of live music and the need to capture in-the-moment experiences.

Originality/value - Whilst each of these theme headings has slightly different meanings and applications to each of the participating stakeholders, the evaluation highlights the potential power of improvised music making to equalise and harmonise the group dynamics by co-creating "in-the-moment" experiences.
\end{abstract}

Keywords Music, Improvisation, Dementia, Care homes, In-the-moment, Manchester Camerata, Qualitative evaluation

Paper type Research paper

\section{Introduction}

Dementia is a terminal and neurodegenerative condition and term "dementia" covers a number of diagnostic variants, the most common being Alzheimer's disease and vascular dementia (Alzheimer's Research Trust, 2010; Alzheimer's Society, 2014a, b; Alzheimer's Society, 2015). Dementia is seen to transition through early, middle and late stages (World Health Organisation, 2016) with people living at the later end of the trajectory requiring help with most, and eventually all, activities of daily living (Alzheimer's Society, 2014a). Progression through these three stages will vary from one person to another, but typically, post-diagnostic life expectancy is estimated at between three and nine years (Xie et al., 2008). However, this will be dependent upon a number of contextual factors, such as age of onset (Alzheimer's Research Trust, 2010) and the presence of any co-existing long-term condition(s), such as cardio-vascular problems
Sarah Campbell is a Research Associate and a PhD Student at the Dementia and Ageing Research Team, University of Manchester, Manchester, UK. Nick Ponsillo is a Director at the Philip Barker Centre for Creative Learning, University of Chester, Chester, UK. Paul Budd is a Head of PR and External Communications at the Care UK, London, UK. John Keady is a Professor of Older People's Mental Health Nursing at the Dementia and Ageing Research Team, University of Manchester, Manchester, UK.

Received 7 January 2016 Revised 12 May 2016 18 August 2016 17 November 2016 Accepted 28 December 2016 
(All-Party Parliamentary Group, 2016). Advanced old age remains the most significant personal risk factor for the acquisition of a dementia (Alzheimer's Society, 2015).

In the UK there are around 850,000 people with dementia, which includes over 700,000 people in England, with the overall numbers of people with dementia in the UK set to rise to over 1 million by 2021 (Alzheimer's Society, 2015). In the UK, around two thirds of all people with dementia live at home with the remaining third resident in a supported environment, such as a care home (Alzheimer's Society, 2014a). Although usually synonymous with a decline in memory and cognitive function, dementia can also affect emotional stability and behaviour and be expressed through behaviours that challenge, such as excessive walking, aggressive acts, intrusiveness and disproportionate vocalisation (Keady and Jones, 2010; van WykJill et al., 2016). Around 90 per cent of people with dementia will experience at least one of these behaviours that challenge during the course of their dementia, particularly at the middle and later stages, and their enduring and cumulative existence are often trigger points for care home admission (James, 2011). Indeed, a report by Alzheimer's Disease International (2013) has reinforced the special needs of people with dementia living in care homes and highlighted that such residents require more personal care, more hours of care and more supervision compared to other resident groups. In response, and over recent years, there have been attempts to move away from viewing behaviours that challenge as a symptom of dementia and, instead, recast such behaviours as the person's attempt(s) at communication as expressed through their body, bodily movement(s) and vocalisation (Kontos and Martin, 2013).

There is, therefore, recognition is emerging that communication is more than the spoken word and alternative ways of developing person-person interaction are needed. As an illustration, in a recent case study on the experience of living with semantic dementia, Kindell et al. (2014) drew attention to the family's need to be adaptable and flexible in supporting Doug's (person with semantic dementia) new interests, such as in dancing, that had previously not been part of his life story. Using the body to express feelings is an integral and intimate part of the human experience which is not lost once a diagnosis of dementia is made; indeed, as in Doug's case, such an embodied need for self-expression becomes a physical reality. Accordingly, to empower and further understand the agency of people living with dementia, artists, therapists and practitioners are responding to such needs through a variety of creative mediums, for example through dance and movement (Coaten and Newman-Bluestein, 2013), theatre performance (Schneider and Myers, 2015), choral works (Harris and Caporella, 2014), poetry readings (Killick, 2008) and musical engagement programmes (McDermott et al., 2013).

On this latter area, the literature on the role of music in the lives of people with dementia, family carers and care environments presents a mixed picture. On the one hand, the literature suggests that music can be viewed as a therapeutic intervention whose aim is to help decrease the person with dementia's sense of agitation and distress when living through its middle/later stages (see e.g. Clair and Ebberts, 1997; Brotons and Marti, 2003; Sherratt et al., 2004; Vink et al., 2004; Raglio et al., 2010; Zeilig et al., 2014). In such circumstances, music as therapeutic intervention is usually undertaken through a controlled trial design and located in a care home environment so that extraneous variables can be minimised by the research team and residents with dementia allocated to either an intervention or control group depending upon the research question and protocol. As an illustration of this approach, Janata (2012) reported on a study that streamed customised music programming (i.e. music played into the individual residents' living environment) at set times over a 12-week period. This music intervention was seen to improve the resident's mood and decrease their levels of agitation, as measured by the Cohen-Mansfield Agitation Inventory, but sustainability of this change over time was not reported. This is a significant limitation to utility, with McDermott et al. (2013) concluding a narrative synthesis of the music therapy and dementia literature with the recommendations that future studies need to define a theoretical model, include better-focussed outcome measures, and discuss how findings improve the well-being of people with dementia.

On the other hand, musical engagement with people with dementia is also reported in the literature as being a participatory, biographically centred and co-constructed activity which celebrates the person with dementia's creativity and well-being (see e.g. Riley et al., 2009; Wall and Duffy, 2010; Killick and Craig, 2012; Killick, 2016). An early example of this participatory 
approach was seen in the work of Pickles (1997) who suggested that "live music is supreme especially when provided by a musician, or group who understand the special problems of people with dementia and are able to interact productively" (p. 20). A number of studies have also begun to address wider factors of what the arts might bring to care settings, for instance how health and social care staff are affected by their engagement in creative interventions and music programmes (Flynn and Chapman, 2011; Sung et al., 2011). Pavlicevic et al. (2015) has named this wider social impact as "the ripple effect of musicking" with Zeilig et al. (2014) calling for a more critical lens in the future conduct of research. It is to this area that we will now turn and to an outline of the Music in Mind programme which bridges both a structured therapeutic approach, in terms of a time-limited engagement, with the improvised creation of music between people with dementia, musicians and those taking part in the group activity.

\section{Music in Mind and Manchester Camerata}

As part of its Health and Wellbeing Community Engagement Programme with hard-to-reach communities, Manchester Camerata, a world-class chamber orchestra and registered charity, in association with music therapists, established the ten week Music in Mind programme for people with dementia living in care homes (Habron, 2013; for additional information: www.manchestercamerata.co.uk/files/pdf/I_p_coventry_musicinmind_evaluation.pdf accessed 17 November 2016). The Music in Mind programme is not about learning to play an instrument, although participants do have access to musical instruments should they choose to hold and/or play them during a session. Instead, the programme is about participants, in this case residents with dementia, care home staff, activity workers, visiting families and a music therapist, engaging in creative musical improvisation together, with that experience played live by the whole group; although led, where necessary, by members of Manchester Camerata. The musical instruments used in the sessions are percussion instruments and not toy instruments typically used by children. Each Music in Mind session lasts between 20 and 30 minutes and includes up to six residents in each session. Musicians taking part in a specific Music in Mind ten week programme are selected based on their availability and who is able to consistently attend delivery sessions. This is deemed essential as it enables trust to be built, and relationships to be formed, across the programme's duration.

Manchester Camerata has a variety of professional musicians available to deliver the Music in Mind programme, including flute, violin, cello, percussion, trumpet, French horn and tuba. All participating Music in Mind musicians attend annual training in dementia awareness, and have an understanding of musical improvisation techniques and music therapy skills. This training is delivered by a music therapist over a period of six separate sessions with related reading in-between attendance.

Whilst there is no fixed agenda to each session over the ten week Music in Mind programme, some structure is present to mark each session and to orientate residents and those attending the group. For instance, all musical instruments are placed in the middle of the room/group and a hello song introduces the participants to the session and a goodbye song ends each session. Outside of these musical bookends, the flow, direction and momentum of each session depends upon a number of factors, such as the numbers of people attending, the time of day the session takes place, any external distractions happening in the care home at that specific moment in time and so on. To promote continuity over the duration of the programme, each session takes place at the same time, in the same room (of the care home), on the same day(s) of the week, with the same musicians (as highlighted earlier) and with as many of the same participating residents/ members as possible.

The care home where the Music in Mind programme took place was part of a large chain of care home providers and those residents living with dementia who attended each session were more advanced in the progression of their dementia, although no independent neuropsychological measures were used by the research team to confirm this statement. The main aims of the study were twofold: to explore the impact and perspectives that taking part in Music in Mind had on participating care home staff; and to better understand the experience of participation from the musicians involved and any visiting family members. 


\section{Study design}

\section{Context}

Over the summer of 2014, musicians from Manchester Camerata and a music therapist attended the participating care home for two days a week for a total of 11 weeks (one week was a rest week). During this period of engagement, a typical day consisted of four planned music group sessions with these sessions supported by either one or two activity workers from the participating care home. The activity workers, alongside care home staff, would help residents to be ready to attend the music sessions in both the morning and afternoon. The same two musicians were in attendance at each session, two of whom attended on one day and a different two on the other. The same music therapist was present throughout all sessions and after each session, the music therapist and the musicians held a de-brief to discuss what had happened during the group and to reflect upon, and refine, as necessary, their practice. The research team applied an exploratory qualitative evaluation technique as a methodological frame of understanding (Patton, 2002).

\section{Methods and sample}

Over the ten week duration of the study, the research team were keen to open up participation in the evaluation to anyone connected with the Music in Mind programme and who had a role to play in its conduct and performance. Interviews did not need to be limited to once-only encounters so that individual contributions could be enhanced and/or an opportunistic interview could be undertaken. In the event, 19 interviews were undertaken with 11 participants over the tenweek duration of the study; interviews were scheduled at time points that were indicated as being convenient by the participants. The interview sample consisted of: one music therapist (interviewed twice); four Manchester Camerata musicians (interviewed twice); two members of Manchester Camerata organisational team (interviewed once); three activity workers (interviewed twice); one care home manager (interviewed once). Family members of people with dementia taking part in the Music in Mind programme were approached to take part in the study but none consented. To provide an illustration of the collected data, interview questions included: "Has anything happened in your communication with residents that is influenced by taking part in the Music in Mind sessions?"; "Is there anything you have noticed in the care home that you can relate to the Music in Mind sessions?" and "What did you do during the group sessions?" These interview questions were initially formulated through discussions held previously by the research team and were based on their collective experience and exposure to this field; however, interviews were semi-structured in nature and enabled respondents to share what was meaningful to them without always being directed by an interview schedule.

In addition, the researcher attended two musician de-briefing sessions in order to get a flavour of how the therapist and musicians worked to enhance their practice by considering each group and what had taken place. This was used as sensitising data for the final interviews. Also three activity workers at the care home were also asked to keep a diary during the ten week period of engagement. A structured set of prompt questions gave direction to help complete the diaries and the first author met with the activity workers once every three weeks to discuss progress. However, at the end of the Music in Mind programme, only two of the activity workers gave permission for their diaries to form part of the overall study data. The first author undertook all the interviews.

\section{Data analysis}

All interviews were transcribed and each activity worker's diary was seen as an integral component of the data set. A thematic approach to data analysis was adopted (Braun and Clarke, 2006); thematic analysis is an iterative process looking to the data for emerging themes and common patterns (Braun and Clarke, 2006). All components that comprised the data set was read and re-read (separately) by two of the authors (SC and JK) and a series of open codes applied to the data (Morse and Field, 1995). A number of meetings were then held between these two authors to compare the initial coding frame(s) and to look for areas of agreement and divergence in the presented data. By continually discussing and refining the coding frames with reference to the source data, an agreed thematic framework emerged that 
helped to explain the main domains and meanings inherent in the data, namely: Making it Happen; Orchestrating Person-centred Care; and Making Musical Connections. It is these three themes that will be reported in this paper. The computer software NVivo 10 was used to help support and sort the data management process.

Ethical approval for the study was granted by The University of Manchester Research Ethics Committee and from the Cheshire East Adult Services Research Governance Department. All participants in the evaluation completed and signed a consent form, were given information about the study and an opportunity to ask any questions before agreeing to take part.

\section{Findings}

\section{Making it happen}

This theme outlined the contextual, structural and organisational considerations necessary for setting up the Music in Mind project. It may be an obvious thing to say, but enabling the Music in Mind sessions to take place at all took a lot of preparatory work by the organisational stakeholders: the care home owner, the care home staff (and activity workers), the care home manager and Manchester Camerata whose initial link was through its Head of Learning and Participation (NP in the authorship). Making it Happen was a relatively long and protracted process, but the data revealed that one of the primary ingredients necessary to turn exploratory negotiations into a working reality was the "can do" attitudes from the care home staff and activity workers, as these extract from the data reveal:

[...] I think you've got to be sort of artistic, which we are, you've got to be a sort of a bubbly personality and be able to sit and talk to anybody, which I can, so you know, you've got to sort of have that personality to do this job, you can't be somebody who's going to walk in grumping and moaning, you know, you've got to leave whatever you've left at home behind you and come through the doors and be that person (care home staff).

These guys [care home staff] they seem to have gone an extra little bit further to accommodate what's happening (music therapist).

There were many practical arrangements and organisational needs to be fulfilled in order to facilitate the running of four Music in Mind sessions on two days per week. However, it was clear that the care home staff, activity workers, Manchester Camerata musicians and music therapist needed to be adaptable and flexible to circumstances in the care home; for example, accepting that residents with dementia may be physically unwell and unable to take part in all the planned sessions, finding out that someone in the care home had died between one visit and the next and/or that the care home was holding an alternative event at the same time as the Music in Mind session. Ultimately, it was important for the participating musicians to hold onto what was of value to themselves and their practice in the performance of their work:

Yeah, we're dealing with a working practice with this music therapy that revolves around providing some ownership for the clients and the residents. Some way for them to feel empowered and to feel a tiny little bit in control perhaps of something. They can make decisions in that room with us. We demand space in the sessions so why wouldn't we have space around it as well? (Manchester Camerata musician).

Making it Happen was not a once-only event. For care home staff, the investment in time and effort necessary to simply help residents attend each of the ten week sessions - on time and be situationally present - should not be underestimated. For example, interviews with care home staff revealed that people with dementia had, occasionally, forgotten what it was they were supposed to be attending and staff reported that residents were, at times, fearful of attending something new and required reassurance about what was about to happen. A crowd of people gathered in one room, together with their possessions and the noise of life, can be an intimidating and personally confronting experience whether you live with dementia or not. Therefore, to help in the orientation process, care home staff took photographs of the resident-musician-care home staff interaction throughout the ten week Music in Mind programme which were prominently displayed in the care home as a memory jogger. 


\section{Orchestrating person-centred care}

Participation in the Music in Mind sessions gave care home staff an opportunity to gain new insights and understandings of residents by viewing the person as being able to take part and to initiate, as this example attests:

I have had a resident that previously has done that in a session [given a tambourine a shake] that I've been in, and they've led it. The musicians have followed it. I've followed it, so they're basically leading the whole group, and it's a resident with dementia and it's pretty impressive I think (care home staff).

The musicians are highly skilled orchestral players and having such musicians gathered in one room playing instruments to such an intense and profound level had a tangible impact on attendees, as one care home participant shared: "It's been good watching the musicians interact with the residents and how they can take on a particular rhythm or the notes that they're following and react to that". Moreover, the musicians themselves felt that they were also learning something new and that there were challenges in performing this kind of work; in particular, that they did not always have to play their primary instrument.

One of the most important aspects of the sessions is that it provided opportunities for communication between residents, staff and families that may not otherwise have taken place, as these three astute observations from the data reveal:

Throughout the sessions the carers have learnt so much about the residents that has been brought out through music, and probably wouldn't have been brought out in other ways. They have been able to enjoy the last moments of someone's life, because quite often, obviously someone with dementia deteriorates, but when they take part in the Music in Mind session, the last moments of their life are really positive (Manchester Camerata organisational staff).

Just seeing from a practice point of view, understanding more subtleties, more different things, different techniques of how to draw out communication from people without forcing anything, like allowing space to let something happen by itself. And we generally in society, and l've always thought this actually quite a lot recently anyway from all the practitioner work that I do, is that we tend to listen to something in order to respond to it directly instead of just taking it for what it is and leaving it sitting out in the open (Manchester Camerata musician).

It's benefited me as well, as an activities co-ordinator it's helped me have a range of experiences with different activities, have a better relationship and communication with the residents, and making music that says they're going to express themselves this way (activities worker).

Developing this latter point, the same activity worker wrote in their diary about how a conversation was sparked by a piece of music that reminded the resident with dementia about how she had met her husband. This person-centred biographical reminiscence led to a wider discussion in the music session and a sharing of stories centred on first encounters with spouses. Residents also communicated with one another in new ways and spent time with different social groups.

\section{Making musical connections}

Care home staff especially seemed deeply affected by seeing residents with dementia empowered by their connections to the musical instruments and to other members of the group: "They're just enjoying what's happening, and it was outstanding". Another care home staff member insightfully revealed that "conversations develop more naturally with music" and it was this musical space that allowed for many relationships to evolve during each and every session. This relational dynamic is best captured in the following two quotations by Manchester Camerata musicians:

There's so many angles that we can all come in at, we've got the clinical perspective, the music perspective, the human element, the care worker element, all of those things coming together in one place, it doesn't really get any [...] I mean could it get any stronger than that? If it could l'd be really fascinated to know what would be the next step beyond that combination of people in a room.

[...] and it's fine because we've both got a good ear because that's what we do and we can just take whatever's happening and roll with that, so it's fine I think. 
Care home staff also recognised the creation of musical connections being made between residents and other group members, with one participant likening it to "a ripple effect", reminiscent of Pavlicevic et al.'s (2015) observation shared earlier in the paper. On the other hand, one of the most significant opportunities provided through the Music in Mind sessions was in being able to support relationships that are both embodied and sensory. The sessions allowed connections to be made that did not solely rely on cognition - or verbal communication - and were therefore inclusive of people living with more advanced dementia.

Making musical connections also meant that the musicians themselves had to connect on a person to person level and not remain disconnected from the audience. This ability to move between roles and identities was crucial to fostering human relationships and making residents with dementia feel at ease in the environment. The following extract from the data best illustrates this phenomenon:

Yes. Yes, we didn't want them to come in and just sit in a corner and play their musical instruments and they didn't. They'd get down on their knees and sit with the residents and help them with the instruments that they chose to play, the residents had chosen, like they'd get down and get involved just like us. They sought to be a one to one with the residents as we were, they'd sit at the side of them and talk to them, and bring them on and we'd laugh together at different things and we'd smile, it was lovely (care home staff).

The development of creative spaces - and what happens in those spaces - was integral to the Music in Mind programme. For those in the room, it was in the intangible mix of improvisation, creativity and, for want of a better word, humanity, that the invisible aspects of the Music in Mind programme became visible. For example, one Manchester Camerata musician described a bond that was created between the participants because of the collective music making: they were described as being "in it together" and of "creating something together". Similarly, examples were shared that highlighted what was happening in the creative musical spaces, as these two experiences shared by Manchester Camerata musicians attest:

[...] You start to look for tiny signals, things that you can latch onto that, you know, a client might offer you something that they would maybe not have felt comfortable doing before, but somehow in that trusting environment in that room after a number of weeks, they feel they can look you straight in the eye and maybe you get a smile from them.

[...] It is quality in this home and it's about quality, but it's also that I have that expertise to be able to play just something different, change subtly all the time and adapt subtly that maybe if you haven't got 30 years' experience, you wouldn't have that subtlety [...].

This resonates with many of the musicians acknowledging the need to be in-the-moment throughout the sessions and it is this presence that also contributes to the atmosphere of the space. The musicians seemed attuned to the vulnerability of the client group and responded by providing space, stillness and gentle interactions and as one musician commented "you have [...] to sort of be comfortable with silences".

Making musical connections was also dependent upon the musicians, residents with dementia, activity workers, the music therapist and care home staff connecting in bodily ways using the instruments, which included connections through a resonator which allows vibrations to be felt from the instrument being played. These musical connections were often embodied and profoundly moving, as this data reveals:

They [resident with dementia] were reaching out to the cello, and then the musician said "Oh yes, of course you can", so the musician had their hand on it and the resident had their hand, and they were playing something lovely and it was beautiful music together. My expression was absolutely wow! I couldn't believe my eyes, what I was seeing because that resident would have looked nothing like that before (care home staff).

The chance to hold and play instruments allowed for bodily and sensory connections and for communication. Having instruments that the residents could hold comfortably was important for the musical space being created and as the weeks went by, the musicians developed strategies that enabled residents with dementia to participate as fully as possible once their individual abilities were identified. To reach such a high level of connectivity in such limited space and time is a testimony to the ambition of the Music in Mind programme. 


\section{Discussion}

This paper has reported on the development of three distinct, but overlapping, themes to help to understand the meaning that live orchestral encounters, under the Music in Mind programme, had on the lives of residents, care home staff, musicians/organisers and activity workers in one care home in the north west of England. Within dementia studies there is an increasing interest in supporting people living with dementia to be recognised as citizens (Bartlett and O'Connor, 2010; Department of Health, 2015). Whilst it is a complex issue, this debate fundamentally concerns how people living with dementia can be empowered to have agency in their everyday lives. For people living with advanced dementia in a care home the need, and opportunity, to express agency is a significant challenge highlighted in previous studies (see e.g. Brown Wilson et al., 2013). However, as seen in this study, the engagement opportunities created by the Music in Mind programme enabled residents with dementia to make choices, to develop relationships and to be part, for a moment in time, of creating something immediate and new.

The participatory arts are known to support social inclusion and improve well-being (Zeilig et al., 2014) and as seen in this paper, communication is more than the spoken word and can be understood as a multi-sensory, connecting and embodied experience. The design did not allow us to gain a longitudinal perspective on (any) environment and staff attitude change brought about by participation, but it was clear to those in the room that people with middle and later dementia enjoyed the Music in Mind sessions, laughed, had fun, made vocal and musical sounds, experienced emotions and connected as a group, and also to the instruments they were holding (and some that others were holding) that provided the sounds. As such, the Music in Mind sessions democratised those in the performance space and for care staff prompted observations that brought new meanings to their care practice. For example, one care home staff member shared how the Music in Mind sessions had seemingly enhanced the time a family carer spent with her mother during the final stages of her mother's life. As the care home worker went on to explain, it was as if the family carer and her mother once again had the opportunity to experience pleasure in one another's company. In another example, care staff shared how a married couple, where one spouse had later dementia, were able to engage in learning something new through the Music in Mind sessions and had found enjoyment together.

With such thoughts in mind, we may need to reconsider the kind of research to carry out when seeking to examine therapeutic value in arts-based projects involving people with dementia, their support networks and the creative force in play, in this case Manchester Camerata. It is clear that understanding how to measure some of the more intangible aspects of a creative engagement process, such as its generating an affective, productive and conducive atmosphere (Wetherell, 2012), poses a notable challenge for researchers (Sherratt et al., 2004; Powell and O'Keeffe, 2010; Spiro, 2010; Wall and Duffy, 2010; Mason, 2011; Gold, 2012). However, there were numerous examples in the data about people with dementia leading musical encounters and performances, some shared in this paper, where everyone involved in improvised music-making activity connected in-the-moment at the same physical, emotional and sensory levels. At such times there was no "them" (people with dementia) and "us" (people without dementia), only an "us". As Kitwood (1997) suggested, such a movement to one shared identity becomes the epitome of person-centred dementia care and personal well-being, a movement fuelled, in this instance, by improvised music making.

How to record such experiences is open to discussion, but the use of video, photographs and other multi-media resources to document such sparks of connection would provide a visual and auditory testimony to the events that took place. Viewed through a different lens, the engagement photographs taken as a memory jogger to remind residents about the Manchester Camerata's visits to the care home and contained positive interactional images involving residents, care home staff, activity workers and musicians. They could be seen as an arts-based translation of evidence into practice (Archibald et al., 2014; Killick, 2016). Measuring immediate and sustained well-being from the Music in Mind programme for care home workers, visiting family, musicians and so on would provide extra layer of evidence. This could be gathered through the longitudinal administration of well-being scales, alongside the real-time and 
in-the-moment experiences of people with dementia. The combined and integrated sum of this whole, we would suggest as the primary outcome measure for assessing a creative arts intervention.

Finally, there is a growing discourse in dementia research and studies around the concept of embodied selfhood which suggests that people with dementia are able to continue to make connections and to be in the world through their bodily selves (Kontos, 2014). As demonstrated through this study and the three themes generated if an opportunity is created which enables live music to be introduced into the lives of people with dementia, it appears it may support embodied selfhood and allow those with advanced dementia to express themselves in unique and relational ways (Kontos, 2014; Phinney, 2014). How this contribution is operationalised presents the next challenge for dementia studies and we hope this paper has provided some early steps towards understanding this.

\section{Study limitations}

First, the request to conduct the evaluation was received about two months before Manchester Camerata's engagement commenced. As these arrangements could not be changed, it did not leave enough time to include in the research ethics approval processes people with dementia who lacked capacity (Department of Health, 2005). Second, a number of family carers were approached to participate in the study but none agreed. We do not have a clear explanation for this, but perhaps they wanted to simply take part in the Music in Mind sessions rather than to view them as research opportunities.

\section{Recommendations for practice and research}

Our primary recommendation for both practice and research is at social well-being should be put at the centre of caring practice, framed around being in-the-moment. This approach widens the lens for viewing support and facilitates new opportunities for engagement, especially for those living with advanced dementia where appropriate word-finding can be a challenging means of self-expression and in upholding self-identity (see also: Wood and Smith, 2004). As seen in this paper, such communication pathways open up new awareness and interventions approaches between residents, staff and family in dementia care which need further study. We would also suggest that this includes the areas of end-of-life and palliative care.

In addition, and as this exploratory study has demonstrated, live music provides a way for people with advanced dementia to express agency and engage in creative self-expression. It is therefore important to consider the multi-sensory environment for people with dementia in practice and research settings and look to capture embodied meanings and expressions, as much as cognitive performance. To take advantage of such opportunities, requires moving into new territories of knowledge and methodological applications that encourage the creation of performance spaces and take a fresh approach to measuring meaning and engagement across multiple domains and time points. The use of video work and sensory methodologies may well help to develop this future research agenda in dementia care and studies.

\section{References}

All-Party Parliamentary Group on Dementia (2016), "Dementia rarely travels alone: living with dementia and other conditions", HMSO, London, available at: www.alzheimers.org.uk/site/scripts/download_info.php? filelD=3008 (accessed 17 November 2016).

Alzheimer's Disease International (2013), "World Alzheimer Report 2013: journey of caring: an analysis of long-term care for dementia", Alzheimer's Disease International, London, available at: www.alz.co.uk/ research/world-report-2013 (accessed 17 November 2016).

Alzheimer's Research Trust (2010), “Dementia 2010”, Alzheimer's Research Trust, London, available at: www.dementia2010.org (accessed 17 November 2016). 
Alzheimer's Society (2014a), “Dementia UK (2014 ed.)", Alzheimer's Society, London, available at: www.alzheimers.org.uk/site/scripts/download.php?filelD=2317 (accessed 17 November 2016).

Alzheimer's Society (2014b), "Dementia 2014: opportunity for change", Alzheimer's Society, London, available at: www.alzheimers.org.uk/site/scripts/download_info.php?filelD=2317 (accessed 17 November 2016).

Alzheimer's Society (2015), "Dementia 2015: aiming higher to transform lives", Alzheimer's Society, London, available at: www.alzheimers.org.uk/site/scripts/download.php?filelD=2700 (accessed 17 November 2016).

Archibald, M.M., Caine, V. and Scott, S.D. (2014), "The development of a classification schema for arts-based approaches to knowledge translation", Worldviews on Evidence-Based Nursing, Vol. 11 No. 5 , pp. 316-24.

Bartlett, R. and O'Connor, D. (2010), Broadening the Dementia Debate: Towards Social Citizenship, The Policy Press, Bristol.

Braun, V. and Clarke, V. (2006), "Using thematic analysis in psychology", Qualitative Research in Psychology, Vol. 3 No. 2, pp. 77-101.

Brotons, M. and Marti, P. (2003), "Music therapy with Alzheimer's patients and their family caregivers: a pilot project”, Journal of Music Therapy, Vol. 40 No. 2, pp. 138-50.

Brown Wilson, C., Swarbrick, C., Pilling, M. and Keady, J. (2013), "The senses in practice: enhancing the quality of care for residents with dementia in care homes", Journal of Advanced Nursing, Vol. 69 No. 1, pp. 77-90.

Clair, A. and Ebberts, A. (1997), "The effects of music therapy on interactions between family caregivers and their care receivers with late stage dementia", Journal of Music Therapy, Vol. 34 No. 3, pp. 148-64.

Coaten, R. and Newman-Bluestein, D. (2013), "Embodiment and dementia - dance movement psychotherapists respond", Dementia: The International Journal of Social Research and Practice, Vol. 12 No. 6, pp. 677-81.

Department of Health (2005), "Mental Capacity Act”, HMSO, London, available at: http://www.legislation.gov. uk/ukpga/2005/9/contents (accessed 17 November 2016).

Department of Health (2015), "Prime Minister's challenge on dementia: delivering major improvements in dementia care and research by 2020", Department of Health, London, available at: www.gov.uk/government/ uploads/system/uploads/attachment_data/file/215101/dh_133176.pdf (accessed 17 November 2016).

Flynn, Z. and Chapman, B. (2011), "Making animated films with people with dementia", Journal of Dementia Care, Vol. 19 No. 6, pp. 23-5.

Gold, K. (2012), "But does it do any good? Measuring the impact of music therapy on people with advanced dementia", Dementia: the International Journal of Social Research and Practice, Vol. 13 No. 2, pp. 258-9.

Habron, J. (2013), “Interim report: Manchester's Camerata's 'Music in Mind' project”, Manchester, available at: www.manchestercamerata.co.uk/files/pdf/__p_coventry_musicinmind_evaluation.pdf (accessed 17 November 2016).

Harris, P.B. and Caporella, C.A. (2014), "An intergenerational choir formed to lessen Alzheimer's disease stigma in college students and decrease the social isolation of people with Alzheimer's disease and their family members: a pilot study", American Journal of Alzheimer's Disease and Other Dementias, Vol. 29 No. 3, pp. 270-81.

James, I.A. (2011), Understanding Behaviour in Dementia that Challenges: A Guide to Assessment and Treatment, Jessica Kingsley, London.

Janata, P. (2012), "Effects of widespread and frequent personalized music programming on agitation and depression in assisted living facility residents with Alzheimer-type dementia", Music and Medicine, Vol. 4 No. 1, pp. 8-15.

Keady, J. and Jones, L. (2010), "Investigating the causes of behaviours that challenge in people with dementia", Nursing Older People, Vol. 22 No. 9, pp. 25-9.

Killick, J. (2008), You are Words: Dementia Poems, Hawker Publications Ltd, London.

Killick, J. (2016), "Creativity and Dementia", in Clarke, C. and Wolverson, E. (Eds), Positive Psychology Approaches to Dementia, Jessica Kingsley Publishers, London, pp. 175-95. 
Killick, J. and Craig, C. (2012), Creativity and Communication in Persons with Dementia: A Practical Guide, Jessica Kingsley, London.

Kindell, J., Sage, K., Wilkinson, R. and Keady, J. (2014), "Living with semantic dementia: a case study of one family's experience", Qualitative Health Research, Vol. 24 No. 3, pp. 401-11.

Kitwood, T. (1997), Dementia Reconsidered: The Person Comes First, Oxford University Press, Buckingham.

Kontos, P. (2014), "Musical embodiment, selfhood and dementia", in Hydén, L.-C., Lindemann, H. and Brockmeier, J. (Eds), Beyond Loss. Dementia, Identity, Personhood, Oxford University Press, New York, NY, pp. 107-19.

Kontos, P. and Martin, W. (2013), "Embodiment and dementia: exploring critical narratives of selfhood, surveillance and dementia care", Dementia: the International Journal of Social Research and Practice, Vol. 12 No. 3, pp. 288-302.

McDermott, O., Crellin, N., Ridder, H.M. and Orrell, M. (2013), "Music therapy in dementia: a narrative synthesis systematic review", International Journal of Geriatric Psychiatry, Vol. 28 No. 8, pp. 781-94.

Mason, J. (2011), "Knowing the in/tangible", Working Paper No. 17, The Morgan Centre, The University of Manchester, Manchester, available at: www.manchester.ac.uk/morgancentre (accessed 17 November 2016).

Morse, J.M. and Field, P.A. (1995), Qualitative Research for Health Professionals, 2nd ed., Sage, London.

Patton, M.Q. (2002), Qualitative Research and Evaluation Methods, 3rd ed., Sage, Thousand Oaks, CA.

Pavlicevic, M., Tsiris, G., Wood, S., Powell, H., Graham, J., Sanderson, R., Millman, R. and Gibson, J. (2015), "The 'ripple effect': towards researching improvisational music therapy in dementia care-homes", Dementia: The International Journal of Social Research and Practice, Vol. 14 No. 5, pp. 659-79.

Phinney, A. (2014), "As the body speaks: creative expression in dementia”, in Hydén, L.-C., Lindemann, H. and Brockmeier, J. (Eds), Beyond Loss: Dementia, Identity, Personhood, Oxford University Press, New York, NY, pp. 120-34.

Pickles, V. (1997), "Music's power, purpose and potential”, Journal of Dementia Care, Vol. 5 No. 3, pp. 20-1.

Powell, H. and O'Keeffe, A. (2010), "Weaving the threads together: music therapy in care homes", Journal of Dementia Care, Vol. 18 No. 4, pp. 24-8.

Raglio, A., Bellelli, G., Traficante, D., Gianotti, M., Ubezio, M.C., Gentile, S., Villani, D. and Trabucchi, M. (2010), "Efficacy of music therapy treatment based on cycles of sessions: a randomised controlled trial", Aging \& Mental Health, Vol. 14 No. 8, pp. 900-4.

Riley, P., Alm, N. and Newell, A. (2009), "An interactive tool to promote musical creativity in people with dementia", Computers in Human Behavior, Vol. 25 No. 3, pp. 599-608.

Schneider, J. and Myers, T. (2015), "Transforming dementia care through theatre", The Journal of Dementia Care, Vol. 23 No. 1, pp. 28-31.

Sherratt, K., Thornton, A. and Hatton, C. (2004), "Music interventions for people with dementia: a review of the literature", Aging \& Mental Health, Vol. 8 No. 1, pp. 3-12.

Spiro, N. (2010), "Editorial: music and dementia: observing the effects and searching for under-lying theories", Aging \& Mental Health, Vol. 14 No. 8, pp. 891-9.

Sung, H.-C., Lee, W.-L., Chang, S.-M. and Smith, G.D. (2011), "Exploring nursing staff's attitudes and use of music for older people with dementia in long-term care facilities", Journal of Clinical Nursing, Vol. 20 No. 11, pp. 1776-83.

van WykJill, A., Manthorpe, J. and Clarke, C. (2016), "The behaviours that dementia care home staff in South Africa find challenging: an exploratory study", Dementia: The International Journal of Social Research and Practice, pp. 1-13, published online before print January 12, 2016, doi:10.1177/ 1471301215622092.

Vink, A.C., Bruinsma, M.S. and Scholten, R.J. (2004), "Music therapy for people with dementia", Cochrane Database of Systematic Reviews, No. 3: Article No. CD003477.

Wall, M. and Duffy, A. (2010), "The effects of music therapy for older people with dementia", British Journal of Nursing, Vol. 19 No. 2, pp. 108-13.

Wetherell, M. (2012), Affect and Emotion, A New Social Science Understanding, Sage, London. 
Wood, N. and Smith, S.J. (2004), "Instrumental routes to emotional geographies", Social \& Cultural Geography, Vol. 5 No. 4, pp. 533-48.

World Health Organisation (2016), "Dementia: fact sheet", available at: www.who.int/mediacentre/factsheets/ fs362/en/ (accessed 17 November 2016).

Xie, J., Brayne, C. and Matthews, F.E. (2008), "Survival times in people with dementia: analysis from population based cohort study with 14 year follow-up”, British Medical Journal, Vol. 336 No. 7638, pp. 258-62.

Zeilig, H., Killick, J. and Fox, C. (2014), "The participative arts for people with dementia: a critical review", International Journal of Ageing and Later Life, Vol. 1 No. 1, pp. 7-34.

\section{Further reading}

Harrison, S., Cooke, M., Moyle, W., Shum, D. and Murfield, J.E. (2010), "Development of a music intervention protocol and its effect on participant engagement: experiences from a randomised controlled trial with older people with dementia", Arts \& Health, Vol. 2 No. 2, pp. 125-39.

\section{Corresponding author}

John Keady can be contacted at: John.Keady@manchester.ac.uk 